\title{
Effect of home based HIV counselling and testing intervention in rural South Africa: cluster randomised trial
}

Tanya Doherty senior specialist scientist ${ }^{12}$, Hanani Tabana senior scientist ${ }^{13}$, Debra Jackson professor $^{2}$, Reshma Naik PhD student ${ }^{4}$, Wanga Zembe senior scientist ${ }^{1}$, Carl Lombard unit director biostatistics ${ }^{1}$, Sonja Swanevelder senior statistician ${ }^{1}$, Matthew P Fox professor ${ }^{4}$, Anna Thorson professor $^{3}$, Anna Mia Ekström professor ${ }^{3}$, Mickey Chopra head of health section ${ }^{5}$

${ }^{1}$ Medical Research Council, Parow, Cape Town, 7535, South Africa; ${ }^{2}$ School of Public Health, University of Western Cape, Bellville, South Africa; ${ }^{3}$ Department of Public Health (IHCAR), Karolinska Institutet, Stockholm, Sweden; ${ }^{4}$ Department of Epidemiology and Center for Global Health and Development, Boston University, Boston, MA, USA; ${ }^{5}$ UNICEF, New York, NY, USA

\begin{abstract}
Objective To assess the effect of home based HIV counselling and testing on the prevalence of HIV testing and reported behavioural changes in a rural subdistrict of South Africa.

Design Cluster randomised controlled trial.

Setting 16 communities (clusters) in uMzimkhulu subdistrict, KwaZulu-Natal province, South Africa.

Participants 4154 people aged 14 years or more who participated in a community survey.

Intervention Lay counsellors conducted door to door outreach and offered home based HIV counselling and testing to all consenting adults and adolescents aged 14-17 years with guardian consent. Control
\end{abstract}

clusters received standard care, which consisted of HIV counselling and testing services at local clinics.

Main outcome measures Primary outcome measure was prevalence of testing for HIV. Other outcomes were HIV awareness, stigma, sexual behaviour, vulnerability to violence, and access to care.

Results Overall, $69 \%$ of participants in the home based HIV counselling and testing arm versus $47 \%$ in the control arm were tested for HIV during the study period (prevalence ratio $1.54,95 \%$ confidence interval 1.32 to 1.81). More couples in the intervention arm had counselling and testing together than in the control arm $(2.24,1.49$ to 3.03$)$. The intervention had broader effects beyond HIV testing, with a $55 \%$ reduction in multiple partners $(0.45,0.33$ to 0.62$)$ and a stronger effect among those who had

\section{Correspondence to: T Doherty tanya.doherty@mrc.ac.za}

Extra material supplied by the author (see http://www.bmj.com/content/346/bmj.f3481?tab=related\#webextra) uMzimkhulu subdistrict showing study clusters

Video on bmj.com (see also http://bmj.com/video)

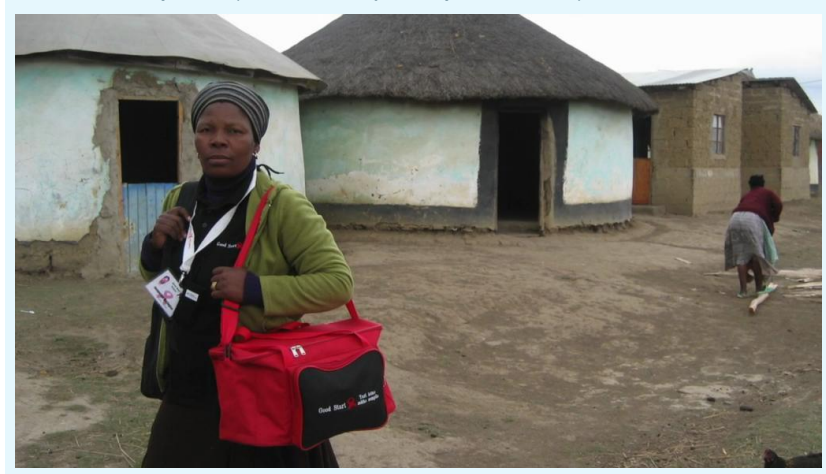


an HIV test $(0.37,0.24$ to 0.58$)$ and a $45 \%$ reduction in casual sexual partners $(0.55,0.42$ to 0.73$)$.

Conclusions Home based HIV counselling and testing increased the prevalence of HIV testing in a rural setting with high levels of stigma. Benefits also included higher uptake of couple counselling and testing and reduced sexual risk behaviour.

Trial registration Current Controlled Trials ISRCTN31271935.

\section{Introduction}

Policy shifts over the past few years in South Africa are making critical HIV prevention and treatment interventions increasingly available. ${ }^{1}$ HIV counselling and testing is the first step in accessing such interventions; however, testing rates remain low. In South Africa, where the national prevalence of HIV in adults in 2009 was $17 \%$ and the antenatal prevalence in women aged $15-49$ years was $30 \%$ in $2010,{ }^{3}$ a 2008 survey indicated that only $25 \%$ of those aged 15-49 years had had an HIV test in the past 12 months and knew their status. ${ }^{4}$ The situation is similar in other sub-Saharan African countries, with Botswana being the only country where more than $50 \%$ of adults aged $15-49$ reported undergoing an HIV test in the past 12 months and receiving their results based on data from demographic health surveys. ${ }^{5}$ In an era where approaches such as HIV testing with immediate antiretroviral therapy ("test and treat") are being considered as a strategy to eliminate HIV transmission, ${ }^{6}$ high population levels of HIV testing are critical.

Expanding the coverage of HIV testing requires innovative approaches such as home based HIV counselling and testing. ${ }^{78}$ Community based approaches to HIV counselling and testing have been implemented in several countries in sub-Saharan Africa, and an implementation handbook has been published by the World Health Organization, ${ }^{9}$ but little rigorous evidence of the effectiveness of this approach exists. ${ }^{10} \mathrm{~A}$ recent Cochrane review ${ }^{11}$ of home based HIV counselling and testing in low and middle income countries identified only one eligible study (a randomised controlled trial in Lusaka, Zambia) for inclusion. ${ }^{12}$ The Zambian study randomised community clusters to HIV counselling and testing either at a local clinic or at an optional location (most commonly the home) and found an almost fivefold (relative risk 4.7) increase in counselling and testing in the optional location group. This trial was undertaken in an urban area and this approach has never been evaluated in a rural setting with a high prevalence of HIV. The Cochrane review concluded that data are insufficient to recommend large scale implementation of this approach. ${ }^{11}$

South Africa seems well suited for home based HIV counselling and testing, given its diverse geography, limited access to healthcare facilities in some high risk settings, varied levels of infrastructure, and epidemiological HIV profile. We assessed the effectiveness of home based HIV counselling and testing compared with facility based HIV testing in South Africa.

\section{Methods}

The home based HIV counselling and testing study was undertaken in the rural uMzimkhulu subdistrict of Sisonke district, KwaZulu-Natal province, South Africa. This subdistrict is in one of the poorest areas in South Africa, where $77 \%$ of households live below the poverty line. The area is characterised by dispersed rural settlements with minimum economic activity, and out-migration to urban centres for work is common. ${ }^{13} \mathrm{~A}$ large proportion of households are headed by women. ${ }^{13}$ Antenatal HIV prevalence in the Sisonke district is 37\%, placing it within the 10 highest HIV prevalence districts in the country. ${ }^{14}$

\section{Study design}

We undertook a cluster randomised controlled trial to assess the effect of home based HIV counselling and testing on the primary outcome, prevalence of testing for HIV. Secondary outcomes included HIV awareness, stigma, sexual behaviour, vulnerability to violence, and access to care. We randomly assigned clusters rather than individuals, thereby avoiding the potential contamination between intervention and control groups and more accurately following the approach that would be taken at scale.

\section{Randomisation}

To limit the risk of contamination between clusters we used census data from Statistics South Africa to demarcate clusters with similar estimated population sizes and suitable borders or natural boundaries (such as roads, rivers, and hills). We undertook a cross sectional baseline household survey in all 16 identified clusters between September and November 2008. Trained data collectors conducted a door to door survey of all adults in the households to collect information on characteristics needed for randomisation: sociodemographic characteristics and history and location of previous HIV testing. ${ }^{15}$ No stratification or matching was deemed necessary based on the results from the baseline survey, and we included all 16 clusters for randomisation. We used simple computer generated randomisation with clusters assigned in a 1:1 allocation ratio (see supplementary figure). Data collectors who undertook the post-intervention survey were different staff from the team implementing the intervention and were masked to the allocation assignment - that is, they were not informed about the cluster allocation.

\section{Home based HIV counselling and testing intervention}

In collaboration with the Sisonke district department of health we developed the home based HIV counselling and testing intervention whereby local women selected from within the intervention clusters were trained as lay counsellors. Only female counsellors were included in this rural area, after consultation with the village chiefs, because it would not have been deemed culturally appropriate for men to counsel women without their husband present and this area is largely headed by women as most men migrate for work. Selection criteria for lay counsellors included completion of 12 years of schooling, residence in the intervention area, and a history of community work.

The intervention team included a clinical nurse supervisor, 11 lay counsellors (three clusters had two counsellors each owing to the distances between households), and four intervention supervisors, who were all from the subdistrict and spoke the local language, a mixed dialect of Zulu and Xhosa. All staff completed a 10 day nationally accredited course in HIV counselling and testing, and the counsellors spent four months being supervised in local health facilities to gain experience of testing.

At the start of the intervention a period of extensive community mobilisation took place. This involved the counsellors having discussions with local chiefs and traditional leaders about HIV and HIV counselling and testing. Through these discussions the community leaders were encouraged to be the first in their communities to be tested. Counsellors also arranged slots to have discussions about HIV and HIV counselling and testing at regular chief gatherings (imbizos), women's meetings, and 
pension days, where leaders and counsellors discussed the importance of HIV counselling and testing.

From September 2009 to November 2010, the lay counsellors carried out door to door visits of all households in the designated intervention clusters. After seeking permission from the household head, the lay counsellors offered free pretest counselling, HIV testing, and post-test counselling to all household members aged 18 years and older. Adolescents aged 14-17 years were also offered testing provided they had parental or guardian consent in accordance with national guidelines. Counsellors were trained to encourage couples counselling and testing.

Lay counsellors gave basic education on HIV/AIDS, after which clients were allowed to make a choice regarding participation. Those who volunteered to participate were then met individually (or as couples) in a private room or section of the home, where pretest counselling, HIV testing, and post-test counselling took place.

The counsellors used the same rapid HIV test kits that were used by district health facilities during the study period: SD Bioline (Standard Diagnostics, Korea) for screening, and SENSA Tri-line (Hitech Healthcare, China) for confirmation of HIV positive test results. Those who tested positive were given a referral letter to be taken to a local healthcare facility of their choice for CD4 testing and other HIV related services. HIV positive clients were also contacted approximately twice by their counsellor after diagnosis to assess progress and access to needed health and social services.

Standard care was available in control clusters, which consisted of HIV counselling and testing services at local clinics and some non-governmental organisation mobile outreach teams. HIV testing in clinics is also generally undertaken by lay counsellors, although it may be undertaken by nurses if no lay counsellors exist. Midway through the study, in 2010, a national HIV counselling and testing campaign was launched by the minister of health. ${ }^{16}$ The campaign aimed to promote HIV testing in clinics and government hospitals and in mobile units going from clinics into communities. Home based testing was not part of the campaign. The target was to test 15 million South Africans by June 2011. This cointervention took place in the subdistrict where our trial was based; however, after discussions with the district it was decided that the campaign would only be implemented in the control communities since our intervention was already delivering HIV counselling and testing services in the intervention communities and would contribute to the district campaign targets. No radio or other mass media was used to communicate about the campaign.

\section{Data collection}

A household survey was undertaken between February and May 2011 in the 16 randomised clusters, approximately 18 months after the start of the intervention, to measure primary and secondary study outcomes. The primary outcome was collected at baseline and post-intervention, whereas the secondary outcomes were only collected in the post-intervention survey. No longitudinal follow-up took place. All households were visited for both the baseline and the post-intervention surveys and no sampling was undertaken. All data were collected on mobile phones in the field and transmitted to a central web based server.

In addition to questions asked in the baseline survey, to develop the post-intervention survey questionnaire we adapted validated questions related to sexual risk behaviour, HIV knowledge, and stigma from other studies in South Africa. ${ }^{17-19}$ Table $1 \Downarrow$ lists the predefined primary and secondary outcomes, number of items for composite indices, and the hypothesised difference between study arms.

\section{Statistical analysis}

We carried out a sample size calculation for the primary outcome, prevalence of HIV testing. The intracluster correlation coefficient estimated from the baseline survey was 0.02 . To detect an increase in the proportion of people who had an HIV test from $32 \%$ to $45 \%$ post-intervention with $90 \%$ power and significance level of 0.05 , we needed eight clusters per arm (16 clusters in total) and approximately 250 participants per cluster. The conservative estimate of effect size due to the intervention was based on rates of HIV testing from national surveys at the time the study was planned. ${ }^{18}$

We summarised continuous measures by means and standard deviations, and categorical measures by proportions. We calculated prevalence ratios for all outcomes. For the main outcome and all secondary outcomes (except for the two outcomes among HIV infected people) we used a hierarchical generalised linear model for the negative binomial family taking into account the design effect by including clusters and households nested within clusters as random effects. The hierarchical model was deemed most appropriate owing to the dependency structure within households (multiple people within a household could have been tested), which needed to be taken into account. We ran this model in SAS. For the two secondary outcomes among HIV infected people we used a generalised linear model for the binomial family with a log link, taking into account the design effect through robust clustering owing to the small size of this subgroup. This model was run in Stata (version 11.0). We assessed potential confounding due to baseline differences in drinking water source, electricity, and ownership of a mobile phone. Inclusion of these factors in the model did not change the estimated prevalence ratio for the main outcome measure.

Subgroup analysis by sex was prespecified and therefore we assessed the homogeneity of the intervention effect by sex. Although we found non-significant interactions between sex and primary and secondary outcomes, for information purposes we present the main outcome stratified by sex. All statistical analyses were by intention to treat.

\section{Ethical considerations}

All participants gave oral informed consent for participation in the study, and written informed consent for HIV testing, in accordance with local district procedures. Information sheets were read and given to prospective participants in the local languages (Zulu or Xhosa) with explanations about the home based HIV counselling and testing intervention.

\section{Results}

All 16 randomised clusters took part in the post-intervention survey and were included in the analysis (fig $1 \Downarrow$ ). Few baseline differences were noted between the intervention and control arms (table $2 \Downarrow$ ). The control arm was slightly better off in terms of infrastructure (more likely to have piped water, electricity, mobile phone ownership). The prevalence of HIV testing was similar across the arms at baseline (table 2).

The prevalence of HIV testing increased between baseline and post-intervention in both arms (32\% to $69 \%$ in the intervention arm; $31 \%$ to $47 \%$ in the control arm), with a greater increase in the intervention arm compared with control arm (prevalence 
ratio $1.54,95 \%$ confidence interval 1.32 to 1.81 ). The intervention effect was similar among men and women (table $3 \Downarrow)$. The most recent HIV test was the first ever such test for $46 \%(640 / 1391)$ of participants in the intervention arm and $37 \%$ (373/997) in the control arm $(\mathrm{P}=0.09)$. Receipt of test results after testing was high in both arms. Among those who had been tested during the study period, the prevalence of HIV was $10 \%$ $(85 / 841)$ in the control arm and 6\% (76/1276) in the intervention arm, which was significant $(\mathrm{P}=0.01)$.

In the post-intervention survey, most $(89 \%)$ of those in the control arm who had been tested during the study period had done so in a health facility, followed by mobile vans (11\%), whereas in the intervention arm most $(58 \%)$ had been tested at home. Few people $(0.6 \%)$ in the control arm reported receiving home based HIV counselling and testing in the post-intervention survey (fig $2 \Downarrow$ ). Among those who had never had an HIV test, the most common reason for not testing was "didn't think I was at risk of getting HIV" (74\% in the intervention arm; $78 \%$ in the control arm).

For secondary outcomes (table $4 \Downarrow$ ) the intervention had positive effects on couple counselling and testing, with double the prevalence of couple counselling and testing in the intervention arm compared with the control arm. Significant effects on sexual behaviour were also noted, where the intervention had a protective effect on having more than one sexual partner in the past three months, which was $55 \%$ lower in the intervention arm. The effect was strongest among those who had been tested (prevalence ratio $0.37,95 \%$ confidence interval 0.24 to 0.58 ). There was a smaller effect on having a casual partner in the past three months, which was $45 \%$ lower in the intervention arm and also stronger (prevalence ratio $0.50,0.36$ to 0.72 ) among those who had been tested. No significant difference was seen in condom use at last sexual encounter or in knowledge about HIV, which was high in both arms.

Participants in the intervention arm were less likely to report stigmatising behaviours, but a difference could not be detected owing to insufficient power. The prevalence of intimate partner violence among those who had been tested and disclosed their status was low in this population, but the results indicate a protective effect against intimate partner violence among those in the intervention arm who had been tested and disclosed their status.

The total sample of participants who tested HIV positive during the study period was small $(n=161)$. Access to CD4 testing was high in both arms and not significantly different.

Among those who reported receiving home based HIV counselling and testing, $85 \%$ rated the quality of counselling received by the lay counsellors as good or very good and only $3 \%$ said that they did not trust that the counsellor would keep their information confidential.

\section{Discussion}

A home based HIV counselling and testing intervention had a significant effect on the prevalence of HIV testing and couple counselling and testing. Furthermore, there was a significant reduction in multiple partners (particularly among those who had been tested) and casual partners in the intervention group compared with control group. The intervention included pretest and post-test counselling on reduction in sexual risk behaviour as well as follow-up of those who were HIV positive. There were no reports of violence or abuse towards the lay counsellors who offered home testing, and participants reported high acceptability of the approach.
We found an increase in HIV testing between the baseline and post-intervention surveys in our control areas. This possibly results from the National HIV counselling and testing campaign, which was launched by the department of health in 2010 . Cointerventions taking place in control areas of cluster randomised trials are recognised challenges of pragmatic trials undertaken in real world settings. ${ }^{20}$ Although the campaign achieved increased individual HIV testing, the home based HIV counselling and testing approach resulted in additional benefits, including reaching more people who had never previously been tested for HIV and most importantly reaching more couples. Furthermore, HIV testing campaigns are one off or repeated resource intensive activities, with no provision for continuity of care. Some people in the intervention arm still chose to be tested for HIV in a health facility $(40 \%)$. The relative contribution of the community mobilisation and lay counsellor home visits in raising awareness and increasing willingness to go and be tested at a health facility is difficult to distinguish. Clearly different options are needed for different individuals; home based HIV counselling and testing in addition to health facility testing services and mobile outreach is necessary to achieve high population level coverage of HIV testing.

The World Health Organization's latest guidelines for couple counselling and testing ${ }^{21}$ encourage greater public health emphasis on couple counselling and testing. Transmission between partners in discordant couples (that is, where one partner is HIV positive) explains a major share of the incidence of new HIV infections in sub-Saharan Africa. ${ }^{22}$ Modelling suggests that mutual knowledge of HIV status would reduce the annual incidence of HIV among discordant cohabiting couples from $20 \%$ to as low as $7 \%$ in Zambia and $3 \%$ in Rwanda. ${ }^{23}$ Home based HIV counselling and testing could also act as an entry point for pre-exposure prophylaxis for discordant couples, which has recently been approved by the US Food and Drug Administration. ${ }^{24}$ The effect of home based HIV counselling and testing on couple counselling and testing may possibly be even larger in an urban area where couples are more likely to live together and do not migrate for work.

This rural region of South Africa was one of the first rural areas to have an antiretroviral treatment programme and is known to have high levels of stigma towards people with HIV/AIDS. ${ }^{25}$ This study also found moderately high levels of stigma, with over a third of control participants reporting that people with HIV are treated badly owing to their status and almost half observing stigmatising behaviour towards someone with HIV/AIDS in the previous year. The positive effect of this intervention on HIV testing, despite the levels of stigma, is encouraging.

Our overall HIV prevalence of $8 \%$ is lower than expected when compared with the HIV prevalence of $25.8 \%$ among those aged 15-49 years in Kwazulu-Natal province. ${ }^{18}$ This may be explained in part by the fact that the mean age of our study population was 41, two thirds were women, the prevalence of high risk sexual behaviour was low, and the area is rural with considerable migration of men for work.

\section{Strengths and weaknesses of this study}

This study had several strengths. The cluster randomised design and large sample sizes for the two surveys reduced selection bias. The trial was implemented under real world conditions using local women as community counsellors with salaries in line with clinic counsellors, district standard operating procedures, and testing equipment obtained from local clinics. These are all strengths of the intervention, which provide 
evidence of effectiveness under routine conditions and supports wider applicability of these results. ${ }^{26}$ Previous studies of home based HIV counselling and testing have largely been descriptive and observational in design. ${ }^{10}$

The study also had several weaknesses. We had low precision of effect estimates for some secondary outcomes, which limited our ability to detect significant differences. We did not ask about long term concurrent partnerships, which may pose a major risk for HIV acquisition. ${ }^{27}$ Outcomes were self reported and could have been subject to social acceptability or recall bias. The questions related to sexual risk behaviour were taken from validated tools with indices of self reported sexual activities, including whether a person has performed the behaviour and how often, stratified by partner type. Furthermore, we restricted the questions related to number of partners to the previous three months and for condom use to the previous 30 days to minimise measurement error. ${ }^{28} \mathrm{~A}$ team not involved in the delivery of the intervention collected the study outcomes. The study did not utilise a longitudinal follow-up design but rather used repeat cross sectional community surveys to measure outcomes. These two designs answer different questions and for the purposes of this study we aimed to assess differences between study arms due to the intervention at a community level rather than only among a subset of people who did not know their status.

The generalisability of these study results should be considered in light of the context. This study was undertaken in a rural, predominantly female headed area of South Africa, with migration of males for work. The mean age of participants was 41 years, reported levels of sexual risk behaviour and intimate partner violence were low and stigma moderately high. This area could therefore be representative of many rural parts of Africa. The intervention should, however, be tested in an urban setting where it may reach younger people with higher levels of sexual risk behaviour.

\section{Implications}

This is the first cluster randomised controlled trial evaluating home based HIV counselling and testing in a rural, high HIV prevalence setting. It provides encouraging evidence that home based HIV counselling and testing by lay counsellors is feasible and acceptable and can have broader benefits beyond the actual testing. In South Africa, the country with the largest number of people living with HIV and the biggest treatment targets, an intervention with a proven effect on testing uptake should be considered for scale-up. The government of South Africa is currently embarking on a revitalisation of the primary healthcare system, ${ }^{29}$ which includes the establishment of a national community health worker programme. HIV testing is currently not in the scope of practice of these national community health workers, although the National Health Act was changed in 2010 to enable lay health workers to conduct finger prick blood testing. There is therefore no legislative barrier to this additional task and it should be considered given the acceptability and effectiveness shown in this study and the minimal additional cost related to training. ${ }^{30}$ Many countries in sub-Saharan Africa are scaling up national community health worker programmes to support their primary healthcare systems, and a recent technical task force recommended that to achieve the millennium development goals, roughly one million national community health workers should be trained and deployed in sub-Saharan Africa by 2015 at a cost of $\$ 6.56(£ 4.31 ; € 5.05)$ per head per year for the rural populations. ${ }^{31} 32$

\section{Conclusions}

This study shows that a home based testing intervention implemented with local counsellors paid salaries in line with clinic based counsellors and using district testing equipment and procedures, can achieve high uptake of HIV testing, increase couple counselling and testing, and lower sexual risk behaviour. Our findings suggest that home based HIV testing should be considered for scale-up as an approach to reach targets for HIV prevention and treatment.

We thank the families, community leaders, and colleagues in the Sisonke District department of health and TB/HIV Care Association for their contributions to this study; the lay counsellors, data collectors, and supervisors (Vuyiswa Mbonambi, Weliswa Binza, Ntombekhaya Sontshebe, Bonakele Duma, and Tandazile Ngezana) for their efforts; Andi Friedman and the team from Clyral for overseeing the mobile data collection; Lorna Madurai and colleagues at Global Clinical and Viral laboratory for quality control; and Natashia Morris of the Health GIS Centre, Malaria Research Unit, Medical Research Council for generating cluster maps.

Contributors: TD, MC, DJ, CL, HT, and WZ oversaw the design of the study. TD, RN, WZ, DJ, and HT oversaw the collection of data. RN, HT, and WZ implemented the study. CL, SS, and TD analysed the data. All authors interpreted the data, prepared the report, and approved the final version. The corresponding author had full access to all the data in the study and had final responsibility for the decision to submit for publication.

Funding: The study was funded by the South African Medical Research Council and by the President's Emergency Plan for AIDS Relief (PEPFAR) through the Centers for Disease Control and Prevention under the terms of 5U2GPS001137. TD and DJ were also supported by the South African National Research Foundation. The study sponsors had no role in study design, data collection, data analysis, data interpretation or writing the report.

Competing interests: All authors have completed the ICMJE uniform disclosure form at www.icmje.org/coi_disclosure.pdf and declare: no support from any organisation for the submitted work; no financial relationships with any organisations that might have an interest in the submitted work in the previous three years; no other relationships or activities that could appear to have influenced the submitted work. Ethical approval: This study was approved by the ethics committee of the South African Medical Research Council (EC09-003).

Data sharing: No additional data available.

The Lancet. South Africa's AIDS response: the next 5 years. Lancet 2012;379:1365. 2 Joint United Nations Programme on HIV/AIDS (UNAIDS). Global report: UNAIDS report on the global AIDS epidemic, 2010.

3 South African National Department of Health. National antenatal sentinel HIV and syphilis prevalence survey in South Africa. South African National Department of Health, 2010.

4 Shisana O, Rehle T, Simbayi LC, Zuma K JS, Pillay-van-Wyk V, Mbelle N, et al. South African national HIV prevalence, incidence, behaviour and communication survey, 2008: a turning tide among teenagers? HSRC Press, 2009.

5 UNAIDS. UNAIDS report on the global AIDS epidemic 2012. UNAIDS, 2012.

6 Granich RM, Gilks CF, Dye C, De Cock KM, Williams BG. Universal voluntary HIV testing with immediate antiretroviral therapy as a strategy for elimination of HIV transmission: a mathematical model. Lancet 2009;373:48-57.

7 Matovu J, Makumbi F. Expanding access to HIV voluntary counseling and testing in sub-Saharan Africa: alternative approaches for improving uptake, 2001-2007. Trop Med Int Health 2007;12:1315-22.

8 Hayes R, Sabapathy K, Fidler S. Universal testing and treatment as an HIV prevention strategy: research questions and methods. Curr HIV Res 2011;9:429-45.

9 World Health Organization. Planning, implementing and monitoring, home-based HIV testing and counselling: a practical handbook for sub-Saharan Africa. WHO, 2012.

10 Sabapathy K, Van den Bergh R, Fidler S, Hayes R, Ford N. Uptake of home-based voluntary HIV testing in Sub-Saharan Africa: a systematic review and meta-analysis. PLoS Med 2012;9:e1001351.

11 Bateganya M, Abdulwadud OA, Kiene SM. Home-based HIV voluntary counselling and testing (VCT) for improving uptake of HIV testing. Cochrane Database Syst ReV 2010(7):CD006493.

12 Fylkesnes K, Siziya S. A randomized trial on acceptability of voluntary HIV counselling and testing. Trop Med Int Health 2004;9:566-72.

13 Umzimkhulu Local Municipality. Reviewed integrated development plan for 2010/2011 Financial Year, 2010. 


\section{What is already known on this topic}

Many countries are struggling to meet targets for HIV prevention and treatment owing to low uptake of facility based HIV testing Home based testing is being promoted in several quarters but without strong evidence of its effectiveness over standard testing A recent Cochrane review, which included only one trial undertaken in an urban area, concluded that more evidence is needed to inform scale-up of this approach

\section{What this study adds}

Home based HIV counselling and testing increased the prevalence of HIV testing in a rural subdistrict of South Africa with high levels of stigma

Benefits also included higher uptake of couple counselling and testing and reduced sexual risk behaviour

To reach HIV treatment and prevention targets this task should be considered for community health workers

14 Department of Health. National antenatal sentinel HIV and syphilis prevalence survey in South Africa, 2009, 2010.

15 Tabana H, Doherty T, Swanevelder S, Lombard C, Jackson D, Zembe W, et al. Knowledge of HIV status prior to a community HIV counseling and testing intervention in a rural district of South Africa: results of a community based survey. BMC Infect Dis 2012;12:73.

16 South African National AIDS Council. Outline of the national HIV counselling and testing (HCT) campaign. South African Department of Health, 2010.

17 Jewkes R, Nduna M, Levin J, Jama N, Dunkle K, Puren A, et al. Impact of stepping stones on incidence of HIV and HSV-2 and sexual behaviour in rural South Africa: cluster randomised controlled trial. BMJ 2008;337:a506.

18 Human Sciences Research Council. South African National HIV prevalence, incidence, behavior, and communication survey, 2008. Human Sciences Research Council, 2009.

19 USAID. Can we measure HIV/AIDS-related stigma and discrimination? Current knowledge about quantifying stigma in developing countries. USAID, 2006.

20 Zwarenstein M, Fairall LR, Lombard C, Mayers P, Bheekie A, English RG, et al. Outreach education for integration of HIV/AIDS care, antiretroviral treatment, and tuberculosis care in primary care clinics in South Africa: PALSA PLUS pragmatic cluster randomised trial. BMJ 2011;342:d2022.

21 World Health Organization. Guidance on couples HIV testing and counselling including antiretroviral therapy for treatment and prevention in serodiscordant couples: recommendations for a public health approach. WHO, 2012.

22 UNAIDS. Together we will end AIDS. UNAIDS, 2012

23 Dunkle KL, Stephenson R, Karita E, Chomba E, Kayitenkore K, Vwalika C, et al. New heterosexually transmitted HIV infections in married or cohabiting couples in urban Zambia and Rwanda: an analysis of survey and clinical data. Lancet 2008;371:2183-91.

24 Karim SS, Karim QA. Antiretroviral prophylaxis for HIV prevention reaches a key milestone. Lancet 2012:379:2047-8.

25 Steinberg J. Three-letter plague: a young man's journey through a great epidemic. Jonathan Ball, 2008.
26 Tunis SR, Stryer DB, Clancy CM. Practical clinical trials: increasing the value of clinical research for decision making in clinical and health policy. JAMA 2003;290:1624-32.

27 Tanser F, Barnighausen T, Hund L, Garnett GP, McGrath N, Newell ML. Effect of concurrent sexual partnerships on rate of new HIV infections in a high-prevalence, rural South African population: a cohort study. Lancet 2011;378:247-55.

28 Catania JA, Gibson DR, Chitwood DD, Coates TJ. Methodological problems in AIDS behavioral research: influences on measurement error and participation bias in studies of sexual behavior. Psychol Bull 1990;108:339-62.

29 South African National Department of Health. Re-engineering primary health care in South Africa: a discussion document. South African National Department of Health, 2010.

30 Menzies N, Abang B, Wanyenze R, Nuwaha F, Mugisha B, Coutinho A, et al. The costs and effectiveness of four HIV counseling and testing strategies in Uganda. AIDS 2009;23:395-401.

31 Singh P, Sachs JD. 1 million community health workers in sub-Saharan Africa by 2015. Lancet 2013; published online 28 March.

32 McCord G, Liu A, Singh P. Deployment of community health workers across rural sub-Saharan Africa: financial considerations and operational assumptions. Bull WHO 2012;91:244-53.

\section{Accepted: 22 May 2013}

\section{Cite this as: BMJ 2013:346:f3481}

This is an Open Access article distributed in accordance with the Creative Commons Attribution Non Commercial (CC BY-NC 3.0) license, which permits others to distribute, remix, adapt, build upon this work non-commercially, and license their derivative works on different terms, provided the original work is properly cited and the use is non-commercial. See: http://creativecommons.org/licenses/by-nc/3.0/. 


\section{Tables}

\begin{tabular}{|c|c|c|}
\hline Indicator & $\begin{array}{l}\text { No of items for composite } \\
\text { indices }\end{array}$ & $\begin{array}{l}\text { Expected difference between study arms due to } \\
\text { intervention }\end{array}$ \\
\hline \multicolumn{3}{|l|}{ Primary outcome } \\
\hline \multicolumn{3}{|l|}{ HIV awareness: } \\
\hline Having had an HIV test & NA & Higher in intervention arm \\
\hline \multicolumn{3}{|l|}{ Secondary outcomes } \\
\hline \multicolumn{3}{|l|}{ HIV awareness: } \\
\hline $\begin{array}{l}\text { Knowledge that someone with HIV/AIDS can look and feel healthy for many } \\
\text { years }\end{array}$ & NA & Higher in intervention arm \\
\hline Disclosed results of most recent HIV test to someone & NA & Higher in intervention arm \\
\hline Received couple counselling with most recent HIV test & NA & Higher in intervention arm \\
\hline \multicolumn{3}{|l|}{ Stigma: } \\
\hline $\begin{array}{l}\text { Agree that people with HIV are treated badly in the community owing to their } \\
\text { HIV status }\end{array}$ & NA & Lower in intervention arm \\
\hline $\begin{array}{l}\text { Any stigmatising behaviours observed in the community in the past year } \\
\text { towards people with HIV/AIDS }\end{array}$ & 17 & Lower in intervention arm \\
\hline $\begin{array}{l}\text { Any stigmatising behaviours experienced by HIV infected individuals in past } \\
\text { year* }^{\star}\end{array}$ & 17 & Lower in intervention arm \\
\hline \multicolumn{3}{|l|}{ Sexual behaviour: } \\
\hline More than one sexual partner in the past three months & 3 & Lower in intervention arm \\
\hline $\begin{array}{l}\text { Any casual partner (any one-off partner or ongoing non-primary partner in } \\
\text { past three months) }\end{array}$ & 2 & Lower in intervention arm \\
\hline Condom use at last sexual intercourse & 3 & Higher in intervention arm \\
\hline \multicolumn{3}{|l|}{ Vulnerability to violence: } \\
\hline Ever been forced to have sex by partner & 3 & Lower in intervention arm \\
\hline $\begin{array}{l}\text { Experience of an episode of physical, sexual, or verbal intimate partner } \\
\text { violence since disclosure of HIV statust }\end{array}$ & 14 & Lower in intervention arm \\
\hline \multicolumn{3}{|l|}{ Access to care: } \\
\hline CD4 count test performed for individuals testing HIV positive & NA & Higher in intervention arm \\
\hline
\end{tabular}

\section{$\mathrm{NA}=$ not applicable.}

*Restricted to those reporting being HIV positive on most recent HIV test.

†Restricted to those who reported disclosing the results of their most recent HIV test. 
Table 2| Characteristics of home based HIV counselling and testing and control arms. Values are number (percentage) of participants unless stated otherwise

\begin{tabular}{lcc} 
& \multicolumn{2}{c}{ Baseline survey (Sept-Nov 2008) } \\
\cline { 2 - 3 } Characteristics & Intervention arm & Control arm \\
No of participants interviewed & 2276 & 2434 \\
\hline Drinking water source: & & \\
\hline Piped into house or yard & $80(4)$ & $460(19)$ \\
\hline Borehole or public tap & $945(41)$ & $566(23)$ \\
\hline Surface water and other & $1251(55)$ & $1406(58)$ \\
\hline Type of toilet: & & $51(2)$ \\
\hline Flush & $2223(1)$ & $2298(94)$ \\
\hline Pit or ventilated improved pit & $20(1)$ & $85(3)$ \\
\hline None or open & $282(12)$ & $702(29)$ \\
\hline Electricity used for cooking & $1704(75)$ & $2034(84)$ \\
\hline Ownership of a mobile phone & $2.6(1.5)$ & $2.9(1.6)$ \\
\hline Mean (SD) No of household members aged $>18$ years & $1579(69)$ & $1585(65)$ \\
\hline Female & $41.5(18.6)$ & $41.4(18.6)$ \\
\hline Mean (SD) age (years) & $140(6)$ & $166(7)$ \\
\hline Education level: & $1040(46)$ & $917(38)$ \\
\hline None & $838(37)$ & $847(35)$ \\
\hline Some primary & $225(10)$ & $358(14)$ \\
\hline Completed primary & $33(1)$ & $146(6)$ \\
\hline Had had an HIV test & & $764(31)$ \\
\hline
\end{tabular}


Table 3 | Estimates of effect of home based HIV counselling and testing on prevalence of HIV testing. Values are number with variable/number in group (percentage) unless stated otherwise

Post-intervention survey (Feb-May 2011)

\begin{tabular}{lccccc} 
Testing for HIV during study period & Intervention arm & Control arm & & Prevalence ratio* (95\% Cl) & Intracluster correlation coefficient \\
\cline { 2 - 3 } Overall & $1392 / 2025(69)$ & $997 / 2129(47)$ & $1.54(1.32$ to 1.81) & 0.03 \\
\hline Women & $1162 / 1541(75)$ & $808 / 1551(52)$ & $1.51(1.29$ to 1.78) & 0.03 \\
\hline Men & $229 / 484(47)$ & $189 / 578(32)$ & $1.52(1.19$ to 1.95) & 0.03 \\
\hline First ever HIV test & $640 / 1391(46)$ & $373 / 997(37)$ & $1.20(0.97$ to 1.49) & 0.03 \\
\hline Test results received & $1376 / 1391(99)$ & $966 / 997(97)$ & $1.02(0.94$ to 1.11) & 0.00 \\
\hline HIV positive result & $76 / 1276(6)$ & $85 / 841(10)$ & $0.65(0.47$ to 0.90$)$ & 0.02 & \\
\hline
\end{tabular}

Data were adjusted for clusters and households within clusters.

*Prevalence ratios for difference between intervention and control arms. 
Table 4| Estimates of effect of home based HIV counselling and testing on secondary outcomes. Values are number with outcome/number in group (percentage) unless stated otherwise

\begin{tabular}{|c|c|c|c|c|}
\hline Outcomes & Intervention arm & Control arm & Prevalence ratio $(95 \% \mathrm{Cl})$ & $\begin{array}{l}\text { Intracluster correlation } \\
\text { coefficient }\end{array}$ \\
\hline \multicolumn{5}{|l|}{ Outcomes within whole sample } \\
\hline \multicolumn{5}{|l|}{ HIV knowledge: } \\
\hline $\begin{array}{l}\text { Knowledge that someone with HIV can look and feel healthy for } \\
\text { many years }\end{array}$ & $1577 / 2024(78)$ & $1853 / 2129(87)$ & $0.86(0.72$ to 1.03$)$ & 0.09 \\
\hline \multicolumn{5}{|l|}{ Stigma: } \\
\hline $\begin{array}{l}\text { Agree that people with HIV are treated badly in the community } \\
\text { because of their status }\end{array}$ & $594 / 2024(29)$ & $818 / 2129(38)$ & $0.79(0.50$ to 1.26$)$ & 0.23 \\
\hline $\begin{array}{l}\text { Any stigmatising behaviours observed in the community in the past } \\
\text { year towards people with HIV/AIDS }\end{array}$ & $822 / 2025(41)$ & $1043 / 2129(49)$ & 0.71 (0.50 to 1.02$)$ & 0.15 \\
\hline \multicolumn{5}{|l|}{ Sexual behaviour: } \\
\hline More than one sexual partner in past three months & $56 / 2024(3)$ & $130 / 2122(6)$ & $0.45(0.33$ to 0.62$)$ & 0.02 \\
\hline Among people who had an HIV test & $30 / 1565(2)$ & $65 / 1283(5)$ & 0.37 (0.24 to 0.58$)$ & 0.01 \\
\hline Among people who have never had an HIV test & $26 / 459(6)$ & $65 / 839(8)$ & $0.73(0.46$ to 1.17$)$ & 0.01 \\
\hline Any casual partner in past three months & $92 / 2024(5)$ & $174 / 2122(8)$ & $0.55(0.42$ to 0.73$)$ & 0.02 \\
\hline Among people who had an HIV test & $57 / 1565(4)$ & $92 / 1283(7)$ & $0.50(0.36$ to 0.72$)$ & 0.01 \\
\hline Among people who have never had an HIV test & $35 / 459(8)$ & $82 / 839(10)$ & $0.79(0.52$ to 1.19$)$ & 0.01 \\
\hline Condom use at last sex & $206 / 868(24)$ & $332 / 1185(28)$ & $0.86(0.65$ to 1.15$)$ & 0.05 \\
\hline Ever been forced to have sex by a partner & $25 / 868(3)$ & $44 / 1185(4)$ & $0.78(0.47$ to 1.28$)$ & 0.01 \\
\hline \multicolumn{5}{|c|}{ Outcomes among people who had an HIV test during the study period } \\
\hline Disclosed results of most recent HIV test to someone & $968 / 1371(71)$ & 709/965 (73) & $0.95(0.77$ to 1.18$)$ & 0.06 \\
\hline$\underline{\text { Received couple counselling and testing with most recent HIV test }}$ & $216 / 1031(21)$ & $76 / 801(10)$ & $2.24(1.49$ to 3.03$)$ & 0.02 \\
\hline Experience of intimate partner violence since disclosing HIV status & 22/968 (2) & $28 / 709(4)$ & $0.57(0.33$ to 0.99$)$ & 0.01 \\
\hline \multicolumn{5}{|l|}{ Outcomes among HIV infected individuals } \\
\hline $\begin{array}{l}\text { Any stigmatising behaviours experienced by HIV infected individuals } \\
\text { in past year* }\end{array}$ & 23/127 (18) & $40 / 127(32)$ & $0.57(0.30$ to 1.10$)$ & 0.08 \\
\hline HIV positive had CD4 count since testing & $67 / 76(88)$ & $74 / 85(87)$ & $1.0(0.89$ to 1.11$)$ & 0.04 \\
\hline
\end{tabular}

Data were adjusted for clustering

*Includes HIV positive individuals who were diagnosed before the study period. 


\section{Figures}

\begin{tabular}{|c|c|}
\hline \multicolumn{2}{|c|}{ Clusters assessed for eligibility $(n=16)$} \\
\hline & \\
\hline \multicolumn{2}{|c|}{ Clusters randomised $(n=16)$} \\
\hline$\downarrow$ & 7 \\
\hline $\begin{array}{l}\text { Baseline survey: } \\
\text { Households approached }(n=1401) \\
\text { Households surveyed }(n=1204 ; 86.0 \%) \\
\text { Household heads refused }(n=8 ; 0.6 \%) \\
\text { Households vacant or no one at home } \\
(n=189 ; 13.5 \%)\end{array}$ & $\begin{array}{l}\text { Baseline survey: } \\
\text { Households approached }(n=1648) \\
\text { Households surveyed }(n=1450 ; 88.0 \%) \\
\text { Household heads refused }(n=10 ; 0.6 \%) \\
\text { Households vacant or no one at home } \\
(n=188 ; 11.4 \%)\end{array}$ \\
\hline$\downarrow$ & $\downarrow$ \\
\hline $\begin{array}{l}\text { Clusters allocated to and received intervention } \\
(\mathrm{n}=8) \text { (average cluster size } 284 \text { people aged } \\
>14 \text { years, range } 219-386 \text { ) }\end{array}$ & $\begin{array}{l}\text { Clusters allocated to and received comparison } \\
(\mathrm{n}=8) \text { (average cluster size } 304 \text { people aged } \\
\text { s14 years, range } 175-449)\end{array}$ \\
\hline $\begin{array}{l}\text { Clusters that did not receive allocated } \\
\text { intervention }(n=0)\end{array}$ & $\begin{array}{l}\text { Clusters that did not receive allocated } \\
\text { comparison }(n=0)\end{array}$ \\
\hline$\downarrow$ & 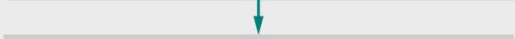 \\
\hline $\begin{array}{l}\text { Clusters lost to follow-up }(n=0) \\
\text { Clusters discontinued intervention }(n=0)\end{array}$ & $\begin{array}{l}\text { Clusters lost to follow-up }(n=0) \\
\text { Clusters discontinued intervention }(n=0)\end{array}$ \\
\hline 1 & $\downarrow$ \\
\hline Clusters included in post-intervention survey $(n=8)$ & Clusters included in post-intervention survey $(n=8)$ \\
\hline Households approached $(n=1753)$ & Households approached $(n=1574)$ \\
\hline Households surveyed $(n=1380 ; 78.7 \%)$ & Households surveyed $(n=1184 ; 75.2 \%)$ \\
\hline Household heads refused $(n=25 ; 1.4 \%)$ & Household heads refused $(n=70 ; 4.4 \%)$ \\
\hline $\begin{array}{l}\text { Households vacant or no one at home } \\
(\mathrm{n}=348 ; 19.9 \%)\end{array}$ & $\begin{array}{l}\text { Households vacant or no one at home } \\
(n=320 ; 20.3 \%)\end{array}$ \\
\hline People approached $(n=2222)$ & People approached $(n=2318)$ \\
\hline People participated $(n=2025 ; 91.1 \%)$ & People participated $(n=2129 ; 92 \%)$ \\
\hline People refused $(n=197 ; 8.9 \%)$ & People refused $(n=189 ; 8 \%)$ \\
\hline Clusters analysed $(n=8)$ & Clusters analysed $(n=8)$ \\
\hline Clusters excluded from analysis $(n=0)$ & Clusters excluded from analysis $(n=0)$ \\
\hline
\end{tabular}

Fig 1 Trial profile

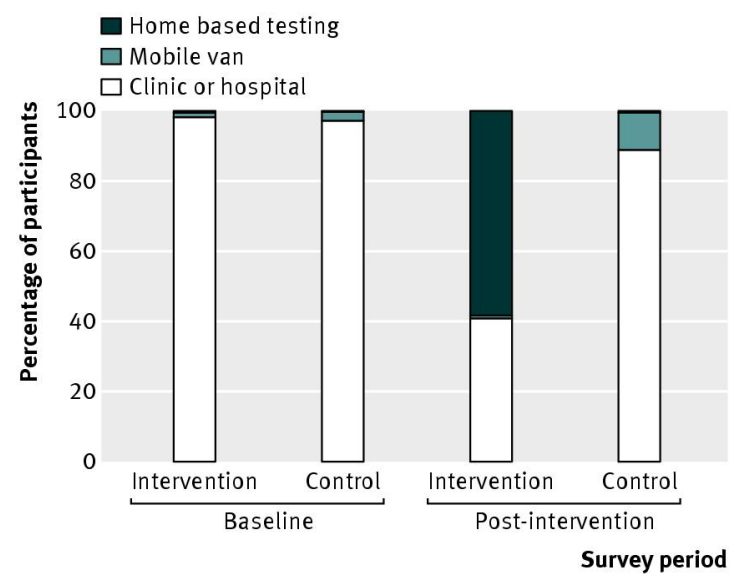

Fig 2 Location of previous HIV test 